\title{
La reescritura de la historia y la nueva novela fundacional puertorriqueña
}

\author{
Rewriting history and the new puertorican foundational novel
}

\section{Luis Milet ti Gaztambide}

\author{
M orehouse Collage. Atlanta, Georgia, EE.UU. \\ E-mail: Imiletti@yahoo.com
}

\section{RESUMEN}

Esta propuesta examina la relación entre los discursos coloniales del poder y la construcción de la identidad caribeña y por extensión la latinoamericana. Este estudio arguye que los discursos del poder y susideologías moldearon la identidad a través dela manipulación y distorsión histórica y literaria. Este artículo se enfoca en las dinámicas historiográficas y en algunas de las anomalías y fragmentaciones que sufre la identidad caribeña. Por ser de corte psicológico, La renuncia de héroe Baltasar nos permite analizar los cambios que $\mathrm{el}$ poder ejerce en la identidad y la auto-percepción.

Palabras claves: Discursos del poder, identidad.

\section{ABST RACT}

This article examines the relationship between the colonial discourses of power and the construction of $\mathrm{C}$ aribbean identity and, by extension, Latin American identity. This study argues that power discourses and their ideologies shaped identity through histories and literature's manipulation and distortion. The article focuses on the dynamics of historiography and some of the C aribbean identity's anomalies and fragmentations. Being a psychological novel, La renuncia del héroe Baltasar allow us to analyze the changes that power discourses exert on identity and auto-perception.

Keywords: Power discourses, identity.

Recibido: 28-08-2007. Aceptado: 12-10-2007.

A HIST O RIA, con h mayúscula, es la historia del poder, es la historia de los vencedores. Se puede decir que la historia no es lo que sucedió, sino lo que se dice que sucedió. La historia siempre se produce en un contexto histórico 
específico, donde los actores son también narradores y viceversa. La historia es un proceso social que envuelve a las personas en tres categorías: "Ios agentes u ocupantes de las posiciones estructurales, los actores constantemente interactuando con el contexto y los sujetos como voces desu propia subjetividad" (Trouillot, 1995: 22). Para rastrear el poder se requiere una visión más amplia de la producción histórica. No se puede excluir a ninguno de los actores 0 a ninguna de las ciudades en las cuales esa producción haya ocurrido. Trouillot indica que los silencios entran en la máquina de la producción histórica en cuatro puntos: el momento de la creación delos hechos, el momento en que se recogen esos hechos (o sea, la creación de archivos), el momento en el cual esos hechos se utilizan (la creación de la narrativa) y el momento de significación retrospectiva (la creación de la historia en última instancia). Los silencios son herramientas conceptuales que nos ayudan a entender el porqué no todos los silencios son iguales y la razón por la cual no se puede hacer un acercamiento a ellos de la misma manera. Cualquier narrativa, ya sea histórica o literaria, es el resultado de un proceso único y las dinámicas requeridas para reconstruir esos silencios variarán de acuerdo con ellos. Los silencios son una parteinherente de la historia porque todo evento entra en ella con la ausencia de algunas de sus partes constituyentes. Algo siempre se queda afuera, mientras que otra cosa es documentada. Esos silencios son también parte de la construcción de la identidad nacional. En el caso de Puerto Rico, la producción de los significantes y silencios por los discursos del poder crearon íconos nacionales (El jíbaro), basados en las ideologías y prejuicios prevalecientes, omitiendo las realidades sociales y demográficas de la época. Este trabajo pretende analizar la producción de significantes y silencios por la elite del siglo XVIII y el XX; examina cómo ellos fueron usados en la construcción dela identidad nacional, además, pretendemostrar cómo la literatura y la historia del siglo XX reaccionaron a la producción de los significantes y silencios en el siglo anterior realizada por los discursos del poder. Este análisis arguye que la construcción de la identidad nacional por parte de los poderes políticos tiene, en el Caribe hispanoparlante, connotaciones raciales.

Es preciso, antes de comenzar, estudiar las fuentes que dieron vida a todas estas dinámicas sociales de corte racial. M ucho antes de queel darwinismo tocara o fuera utilizado por los discursos del poder y su retórica racial, ya para mediados del siglo XVIII los pensadores buscaban formas para evaluar a los humanos en base a un criterio natural y físico. El poligenismo, caso extremo de dicha histeria clasificadora, postulaba que cada raza tenía diferentes orígenes y por consiguiente diferentes especies. Esto, desde luego, se esgrimía por la mayoría de los discursos del poder como prueba fehaciente de la inferioridad mental y moral de los negros. Las ideologías racistas desarrolladas en el siglo XIX fueron precedidas, en Europa, por un antiquísimo prejuicio sobre el color negro que 
hace un paralelo entreel negro y la fealdad, el mal, el pecado, el peligro y lastransgre siones sexuales.

El propósito de esta investigación es analizar los efectos que tuvieron los discursos raciales de la época en la literatura y en la construcción de la identidad nacional puertorriqueña. Con esta intención se ha escogido La renuncia del héroe Baltasar ${ }^{1}$, ya que es representativa de las dinámicas del poder en la construcción nacional y racial de Puerto Rico. Este estudio aplicará teorías sobre el poder y explorará anomalías en la psique del negro durante la colonia. Esta novela a-histórica de Edgardo Rodríguez Juliá presenta dos fuerzas antagónicas que, personificadas por el 0 bispo Larra y don Baltasar M ontañez, luchan por el poder y el control de la sociedad. En el texto se observa una continua transferencia del poder con connotaciones raciales. Se puede atisbar un deseo por reescribir la historia puertorriqueña, dándole al negro un lugar en la formación cultural y racial de la isla.

Para establecer la relación entreel poder y la identidad a través de la literatura, en La renuncia del héroe Baltasar, será necesario deconstruir, primeramente, la estructura del poder en la novela y evaluar sus dinámicas. En segundo lugar, este análisis se detiene en los personajes y los efectos que ejerce el poder sobre ellos. En tercer lugar, se ahondará en las problemáticas de la identidad puertorriqueña que se reflejan en el texto. Por último, se revisarán las propuestas del texto y su impacto en las letras puertorriqueñas. Prácticamente todalaacción de la novela es un ejercicio de poder. Cohabitan en ella cuatro discursos de poder: el militar, el eclesiástico, el civil y el legislativo. En el relato las dinámicas del poder trabajan en términos de relaciones, son más bien luchas entre los grupos. Lo que caracteriza estas relaciones es que no son definitivas y son muy volátiles. Los constantes cambios del poder, en conjunto con cambios en alianzas, pueden ser observados en detalle. La Corona o la metrópoli española, la elite criolla puertorriqueña, la I glesia C atólica y Baltasar, representan las corrientes del poder en esta novela. En la literaturización hiperbólica de las rebeliones negras de Rodríguez Juliá, el poder se presenta como una fuerza destructora. D eestemodo, la destrucción de las haciendas es significativa ya que para muchos doctos en la materia esas haciendas eran el depositario de la cultura puertorriqueña. Al describir la destrucción de la infraestructura de la economía, la devastación de los campos y las sangrientas masacres perpetradas por los negros revolucionarios, el Redactor Privado Adjunto de G obernación y Asuntos Civiles describe a los negros como seres que apenas llegan a humanos y que poseen un gran vacío allí donde en nosotros reside el alma (80). El poder en las manos de los colonos y

${ }^{1}$ Todas las citas a la novela de Edgardo Rodríguez Juliá, publicada en 1974, corresponden a la edición de 1986 realizada por Editorial Cultural. 
criollos, sin embargo, se corrompe con chantajes, manipulaciones eintrigas. El dominio del 0 bispo Larra es el microcosmo del poder que ostentaba Ia I glesia en general. Para Foucault, "el poder de Dios es el poder que controla la moralidad y por ende la sociedad, de allí que las religiones no son solamente sistemas simbólicos de lo divino y de lo invisible sino también de la configuración del orden" (Danaher, Schirato y Webb, 2000: 72). El O bispo manipula la religión, el gobierno local, los archivos históricos y legales y a la sociedad en general. Su potestad trasciende lo eclesiástico para internarse en lo político, sobrepasando los límites de la moralidad. Por otro lado, Baltasar cuestiona las ideas del racismo científico que patrocinaba Ia I glesia. La novela también propone dos ideas muy modernas del poder y sus mecánicas. La primera es queel poder viene de la gente y que ésta elige a su líder. Lejos de haber una democracia en el relato de Rodríguez Juliá y en el Puerto Rico del siglo XVIII, Ios negros sublevados exigen la reinstalación de Baltasar como jefe de la plaza de San Juan por medio de la fuerza. Pero esta idea de que el poder proviene de la gente prueba ser tan falsa en ese período como en el siglo XX.

Foucault indica que "if we look at history in the twentieth century we will find that it is not a case of the people holding power, or even delegating power to individuals or groups, but a case of groups becoming powerful by standing in for the people, or by claiming to speak for or represent the people" ( $D$ anaher et al., 2000: 73). De manera que mediante esa representación del pueblo por la elite se construye o reconstruye la identidad. En La renuncia del héroe Baltasar, el poder actúa o es ejercido sobre la gente de una manera no igual itaria, siempre al gunos grupos son oprimidos por las mecánicas mismas del poder. Baltasar afirma que la destrucción total de las bases de la actual sociedad es la única manera de remediar los atropellos cometidos en un pasado. Le explica al 0 bispo Larra, en una carta, que no puede acceder a su petición de piedad por las madres de los hijos asesinados a manos de esclavos revoltosos, porque "pedir compasión a un hombre de verdad es hacerlo cómplice de la mentira que ha sido fabricada, día a día, por la desenfrenada astucia, porque es reverso de la piedad" (89). Su mayor poder, dice, es la renuncia a la compasión. En la novela, el O bispo pretendía ascender a Baltasar temporalmente al gobierno mientras calmaba los ánimos de los negros y les daba una sensación de poder. No contó con que se revelarían aún más con el encarcelamiento de su ídolo y líder.

D e los poderes y sus discursos el más débil o ausente es el de la Corona española. Sus breves apariciones en el texto son utilizadas por otros discursos como última opción para la resolución de sus agravios. Es un imperio ausente que indirectamente, en cuanto al texto se refiere, no tiene mucha influencia sobre las dinámicas del poder que se desarrollan en la isla de Puerto Rico. El poderío de la Corona está representado en este texto como un organismo 
referencial. Los discursos de la monarquía son importantes no por el poder en sí, sino por las ideologías y convenciones de toda una época que fueron creadas e institucionalizadas por ella. La importancia del poder como determinante de las relaciones entre grupos está reflejada en el rol de la Iglesia y la metrópoli en las situaciones coloniales. La supremacía católica en esta novela está fracturada en una composición tripartita. Los altos funcionarios en Puerto Rico y el 0 bispo Larra, que actúa por su cuenta, representan dos niveles del dominio en disputa por el control social y eclesiástico de la isla. Por otro lado, la I glesia (institución) representa el poder ausente y referencial. Su poder, en todos sus niveles, sirve de contrapunto al poder del negro.

En la novela, el comportamiento de los negros revoltosos compagina con las ideas que Baker propone con respecto al poder y sus relaciones. Baker indica que "los grupos étnicos y raciales, sean los grupos dominantes o no, subordinados o en igual posición, movilizan sus recursos y se esfuerzan por obtener el control sobre las estructuras políticas, económicas y sociales de la sociedad" (1981: 25). Cuando a un grupo le es prohibido o no puede conseguir sus metas dentro de esas estructuras, es posible que recurra a otros medios como la revolución para alcanzar sus objetivos. Este es el caso de los negros revolucionarios en la novela. En ella los grupos que disputan el predominio lo debaten en dos ámbitos, el político y el económico. D entro de esas arenas existen dos tipos de decisiones políticas de mayor importancia. La primera es la decisión estructural y la segunda son las resoluciones de política cultural. La primera defineel grado de acceso e incorporación que tiene cada grupo dentro de la estructura, y determina sus recursosy poderío. Las decisiones de política cultural pueden dividirse entre dos polos: aquella que trata de eliminar la cultura de los subalternos e imponer una cultura "nacional"; y la política de multiculturalismo, o sea, la que acepta la legitimidad cultural de los subalternos. En el texto de Rodríguez Juliá los dos bandos, encarnados en el O bispo Larra y en Baltasar, rivalizan por la supremacía política y económica de la isla. La autoridad católica trata de mantener a los negros bajo el yugo de la esclavitud mientras que aparenta darle más acceso al poder. D entro de las convenciones culturales ejercidas por la I glesia y la Corona, el 0 bispo intenta denigrar y eliminar la cultura africana y psicológicamente imponer la cultura occidental. La descripción de la singular celebración por parte de los negros de la boda de Baltasar y Josefina, festividad que dura una semana, revela dos cosas. Tanto el 0 bispo como los blancos en general padecían de una falta de conocimiento de la cultura africana y exhibían una percepción animalizada de la cultura negra.

Lastimosa visión ha colmado mis ojos. La rosa de flor niña Josefina aturdida por la música frenética de esta impúdica y salvaje raza de carbón, vaga por las 
calles junto a su criminal esposo, sus ojos cansadísimos de tanto diabólico insulto, sus ropas manchadas por la ignominiosa afrenta de todas aquellas muchas manos que más son de simios que de hombres. $Y$ al lado de las harto virginales y blancas margaritas de sus manos, retumban las negras pezuñas sobre los tensos cueros de los tambores (35).

En la novela las acciones de los subalternos están total mente circunscritas al poder. En ella aparecen las dos opciones que menciona Baker en su estudio sobre las relaciones de poder. La primera es la oposición, que puede llevar a la revolución 0 a formas más subliminales como la subversión. La segunda es la conformidad, que puede ir desde la retracción hasta la emanación, o sea, una situación donde los subalternos se deshacen de su propia identidad y cultura por la cultura del grupo dominante. La presencia del dominio psicológico en La renuncia del héroeBaltasar se expresa de diversas maneras. Baker argumenta que "three categories of psychosocial dominance are evident. These psycho-social states can be classified as compliance, dependency and thought control" (1981: 35). D ichas clasificaciones encajan a perfección con el texto y están presentes tanto en Baltasar como en los negros esclavos.

La conformidad es la primera categoría de dominación psíquica. En este nivel la elite utiliza tácticas de coacción y recompensa para mantener el poder. Es mediante esa coacción queel 0 bispo lleva al poder a Baltasar y es a través de éste que mantiene momentáneamente contentos a los negros. La segunda categoría de sujeción psicológica es la dependencia. En la novela es posible apreciar cómo los negros revolucionarios, aunque aparentemente en control, dependen de su líder para obtener la dirección y liderazgo del cual carecen. La última categoría de predominio psicológico es la del control del pensamiento, quepuede ser definido como imperialismo cultural o deculturización. Su misión principal es destruir la identidad cultural de los grupos subalternos por parte de los grupos en control. Las ideas de Bakhtin arrojan valiosos aspectos sobre las diná micas del poder en La renuncia del héroe Baltasar. Bakhtin (Bravo, 1987: 40) indica que existe un deslinde entre las novelas que llama monológicas, reducidas a una perspectiva discursiva que jerarquiza y redistribuye las diferentes discursividades; y las dialógicas, que sitúan en interrelación los diversos estratos discursivos y pone ante el lector las disímiles perspectivas sin tomar partido por ninguna. Esto nos ayuda al análisis de la novela, ya que contiene cierta hibridez con respecto a lasideas deBakhtin. $D$ emanera quese puede argumentar que La renuncia del héroe Baltasar es monológica, ya que el discurso occidental y colonial que personifica el 0 bispo Larra tiene una tendencia jerarquizadora, tendencia que de hecho tiene serias repercusiones en la formación de la identidad. Por otro lado, no se debe menoscabar la vena dialógica del relato, ya que se 
logran fácilmente atisbar las tensiones entre el poder absoluto y el colectivo. Al leer esta novela se puede concluir que el poder no solamente persigue un objetivo político, sino quetambién procura un objetivo ideológico de corte racial que se filtra entre las instituciones y en las formas de intercambio social.

Siendo La renuncia del héroe Baltasar una novela a-histórica, parodia los discursos del poder y en ocasiones cuestiona los mismos textos históricos produciendo otros informes que disputan la veracidad de los primeros. Rodríguez Juliá ahonda en la intrahistoria de la sociedad puertorriqueña del siglo XVIII para así rescatar otra versión del génesis racial de su pueblo. A pesar de ser un texto a-histórico, su estructura basada en reportes, entrevistas, crónicas, cartas, conferencias por parte del catedrático y la constante aparición de fechas le da un tono histórico. El autor literaturiza los vacíos históricos y las mecánicas del poder recreando de esa manera el nacimiento de las anomalías de la identidad puertorriqueña.

En cuanto a la historia se refiere, el catedrático-narrador dice, acerca de Baltasar, que "su estancia histórica está entre la gran historia y la intrahistoria" (8). El narrador pretende rescatar la figura del héroe desde las profundidades de la intrahistoria y lo sitúa como pilar de la composición racial puertorriqueña y como parte integral de su pasado. Al igual que tantos subalternos, la vida de Baltasar desapareció de los anales de la historia precisamente por los vacíos creadospor los historiadores. Las conferencias del narrador constituyen un estudio en proceso donde las hipótesis sobre hallazgos son redefinidas por otros documentos que arrojan más luz a la trama y a la intrahistoria. Es por esto que este estudio considera que la novela apela a una deconstrucción de la historiografía puertorriqueña para identificar los vacíos históricos y llenarlos. Un ejemplo es la mención, en las crónicas del país, de la asistencia del depuesto general Prats a la boda de su hija. Esta burda mentira muestra las intrigas del poder por el control social o religioso. Aun cuando el capitán de la plaza no asistió al matrimonio, todas las crónicas, excepto una, mencionaron su presencia en las nupcias de su hija. La crónica que mencionó su ausencia fue obligada a retractarse por orden del O bispo. Rodríguez Juliá continúa subvirtiendo la historia oficial cuando nuestro conferencista-narrador nos deja saber que al gunas de las adiciones hechas a una de las crónicas de 0 viedo se le atribuyen a Baltasar. El estilo de Baltasar es, dice el narrador, "hinchado, redundante y versado en retórica, resultado de una asimilación cultural realizada con mucha prisa" (18).

El hecho de que el novelista proponga o coloque, dentro del siglo XVIII, a un negro como protagonista se convierte en una subversión psicológica, histórica, social, racial, en fin, una máquina de subversiones. El autor va más allá, dándole a Baltasar el poder de la palabra escrita. El conferencista e historiador 
indicaque "las adiciones hechas a la crónica de 0 viedo selas atribuimos a Baltasar. La grafía de estas adiciones corresponde a la de varios manuscritos de Baltasar que conservamos" (18). Este héroe tiene la atribución suficiente para adulterar la historiay así obedecer a las mismas fuerzas y dinámicas queledieron el poder, hecho que demuestra que las mecánicas del poder van más allá de razas y obedecen más a intereses creados. El 0 bispo admite que el control de la sociedad, 0 sea del populacho, por un manojo de personas se ha obtenido a través de una sucesión de mentiras. Al excusarse, en nombre de la Santísima I glesia C atólica y categorizando a los mentirosos como buenos cristianos y a las mentiras como piadosas, segmenta la sociedad a través del crisol de la cristiandad entre la elitey los subalternos. O pina que en el caso de Puerto Rico, olvidado por España, sólo la fey el temor a Dios logran controlar a los negros y se puede extrapolar que el 0 bispo cree que sólo a través de la religión se puede humanizar a los que clasifica como bestias. El prelado le escribe a Baltasar:

Para usted el poder civil y eclesiástico, que en mi persona sostengo, es la cárcel de los hombres; cárcel fabricada con la sucesión de mentiras que por los siglos han sido menester para la buena y dulce convivencia de los humanos. Pero estas mentiras, que los buenos cristianos calificamos como piadosas, son la única garantía de que el hombre no se convirtiera en la más temible bestia (91).

Esel 0 bispo Larra quien conformala leyenda del mito histórico y milagroso de Baltasar. Son los discursos del poder, en manos del religioso, los que crean su imagen por razones políticas.

En la creación de una política reformista y para el apaciguamiento de los negros, el O bispo utiliza a Baltasar como una marioneta. La creación de su mito, el matrimonio con una mujer blanca de sociedad y su ascenso al mando civil de la Plaza de San Juan fueron tejidos por el prelado para controlar a los negros y por ende a la sociedad, y de esa manera evitar algo que años después sucedería en $\mathrm{H}$ aití. En esta novela hay una inversión parcial de roles donde los negros pasan de ser subalternos a compartir el poder momentáneamente. La retórica del 0 bispo solamente se explica partiendo de la concepción de que el blanco es mejor que el negro, ya que con las matanzas e insurrecciones los negros están violentando el plan divino que los excluía. En su diario, refiriéndose al poder, el 0 bispo articula su naturaleza escurridiza y el delicado balancequelo constituye donde se conjuga el bien y el mal, la justicia y la injusticia: "Q uélejos me encuentro de él, yo, que he vivido el poder como delicado compromiso entrela compasión y el terror" (99-100). D emodo queel poder afecta tanto ala elite como al subalterno y su posesión trae complicaciones inherentes.

Las convenciones raciales de la época son expuestas cuando el líder católico 
le propone a Baltasar que conduzca a los negros por el camino de la paz y la obediencia. Le plantea, además, que acepten las convenciones sociales del momento y que asuman su condición de negros bajo la estructuración del plan divino. Se puede de esa manera situar a Baltasar con Enriquillo en la novela del mismo nombre, ya que a ambos se les exige que admitan su rol de subalternosy sus penurias como parte de ese designio. Para el $\mathrm{O}$ bispo el deseo de los negros por romper las cadenas era anómalo y diabólico. Además le atribuye a Dios el plan de mantener a los negros oprimidos. Convirtiendo una ideología en decreto divino, seduce a Baltasar con el poder que le ofrece y de paso lo utiliza para mantener firme las bridas del desbocado caballo que es su raza. M ientras que el 0 bispo sataniza a la raza negra, se refiere a la suya como poseedora de "nuestra natural privilegiada condición" (13).

Por medio del matrimonio de Baltasar con Josefina se logra adormecer la conciencia del negro y se minimiza la posibilidad de una revolución. Como en Enriquillo, el apaciguamiento selogra transitoriamente. La población esclava es confundida con la ilusión de la libertad. "El Ilamado Baltasar desempeña a perfección suma su papel conciliatorio entre las dos razas que habitan esta grácil y bella isla" (13). Si el 0 bispo es el arquitecto y representantede las dinámicas del poder, Baltasar es el instrumento del poder. Rodríguez Juliá hace un Ilamado a la inclusión de los negros como parte de la composición racial puertorriqueña, pero, como se observa en la novela, esa inclusión destruye los cánones ya establecidos. 0 sea que la total aceptación de las raíces africanas destruiría la imagen de la esencia puertorriqueña como blanca o por lo menos no negra, que se ha ido elaborando a través de los siglos. El análisis del poder que ostenta Baltasar ahondará además en las diversas consecuencias y simbolismos que repercuten sobre la identidad puertorriqueña. Su dominio es excepcional ya que no tan solo es el único poder individual ajeno a cualquiera institución o elite, sino que él es en esencia un vacío histórico y hasta que las conferencias del catedráticonarrador no comenzaron su persona era desconocida. Su matrimonio con Josefina Prats le permitió humillar a los blancos personal y simbólicamente, a nombre de los negros que de alguna forma buscaban satisfacer su ira contra los blancos que habían mancillado y violado a tantas mujeres negras. Pero Baltasar reconocía "la incapacidad del negro - depositario de las pasiones del esclavo y su psicología- para lograr la humillación del blanco" (55). Ya que ese propósito era de gran importancia paraél, debido a que la perseguía a nombre de su raza, en uno de los pasajes de sus manuscritos dice: "En mí aúlla el deseo de toda una raza; pero he aquí que no es un deseo de placer, sino de humillación" (55). La degradación del blanco era de gran valía ya que "se ordenaba que la sujeción hacia el blanco sea total por parte del negro. Por tanto, todo negro esclavo o libre, par- 
do, primerizo, segundón o tercerón y en adelante será tan sumiso y respetuoso a toda persona blanca como si cada una de ellas fuera su mismo amo o señor del siervo" (Sued Badillo y López Cantos, 2001: 245). La humillación de Josefina pasó a ser un bálsamo psicológico para Baltasar y los negros de la isla.

Esta humillación no se limita al mero matrimonio de un negro pobre con una blanca privilegiada, sino que va más allá de las diferencias clasistas o inclusive de las uniones interraciales. La sexualidad en el matrimonio de Baltasar y Josefina revela importantes perspectivas entre la identidad y las relaciones interraciales. Primeramente la descripción de los apetitos y preferencias sexuales de Baltasar son acordes con las ideologías europeas prevalecientes en esa época. El abandono a las pasiones y la promiscuidad del negro, de acuerdo con los europeos, se hace presente cuando el narrador describe las orgías que llevan a cabo en las inmediaciones del palacio degobernación. Pero estas orgías, lejos de solamente corroborar un estereotipo de la sexualidad del negro, se enlazan directamente con la deshonra de Josefina Prats. El conferencista-narrador indica que todo su comportamiento hacia Josefina se originaba "en su velado sentimiento de... inferioridad" (55). Este sentimiento de Baltasar no le permite consagrar su matrimonio. La humillación de Josefina se efectúa cuando él organiza sus orgías en el cuarto contiguo al suyo, donde ella mientras oía los gemidos se masturbaba. La relación entre ambos personajes merece nuestra consideración como fuente importantísima para el estudio de la identidad. Para analizar este episodio se utilizarán las ideas del gaze como se examinan en Black skin, white mask. Se dividirá la mirada o gaze en tres partes: la vigilancia, la fragmentación de la autopercepción (racial/psicológica) y la sexualidad en la mirada (Fanon, 1967). A través del gaze se produce la vigilancia y la vigilancia a su vez es una expresión de poder. La mirada, como otras expresiones físicas, expresa el poder y sus discursos. Bravo indica que "la mirada expresa muchas formas del poder, y una de ellas es que jamás miramos de igual a igual; aunque sea de manera sutil, la mirada establece sus jerarquías para destacar unas cosas y otras no, para mirar sin ver o para que el objeto mirado se ilumine" (1987: 42). En las crónicas y misivas que aparecen en esta novela se puede observar un patrón de vigilancia y análisis de los sujetos. Las descripciones bestializadas de los negros y el psicoanálisis que el 0 bispo realiza a Baltasar, y que redacta en sus notas, son muestra de la vigilancia que ejerce el poder sobre los subalternos. Sólo la observación detallada y constante puede relatar con tanto lujo de detalles las actividades de los negros y la manera de pensar de Baltasar. Por ejemplo, de la descripción pormenorizada que hace el $O$ bispo Larra de la fiesta matrimonial se desprende una impresión de que los negros son vigilados en todo momento por la presencia militar durante esa celebración. 
La fragmentación de la autopercepción de Baltasar sucede inmediatamente después de la boda cuando se establecen las normas dentro su matrimonio. Esta ocurrea través dela mirada y señala la completa adopción de la cultura occidental por su parte. Este, antela mirada deJ osefina, se percata de que es una imitación del colonizador. Se da cuenta de que su esencia colonial era una total despersonalización de su identidad. La imagen propia que tenía Baltasar, y que había construido en parteel $\mathrm{O}$ bispo Larra, se fractura con este matrimonio. "El cuerpo de Josefina se convirtió en 'tentación de inferioridad' según sus propias palabras" (54). Su autodespersonalización viene adjunta a unas connotaciones sexuales y éstas a su vez están ligadas a la mirada, ya que la mirada implica, en este caso, un aspecto sexual. D e acuerdo con Fanon, el negro viene a ser el centro de la mirada sensual izada. Este no desea a la mujer blanca, pero la mujer blanca lo desea. Es pertinente recordar que Josefina aparece masturbándose mientras observa una orgía. Ella niega su deseo por la presión que ejerce el racismo. Se debe analizar, primeramente, las aprehensiones que tiene Baltasar con respecto a la consumación sexual de su enlace. El narrador se adentra en la psique del personaje cuando nos dice que este casamiento fue "concebido por él como un medio de humillar al blanco, de satisfacer, en alguna medida, el anhelo de los negros cuyas mujeres habían sido ultrajadas" (53). En la mirada deBaltasar hacia Josefina no hay deseo sino venganza, la pretensión a reparar de algún modo los agravios hechos. Por otro lado, su orgullo le impide completar el acto sexual ya que se considera un "victimario despreciado" (54). El desprecio, arguye este estudio, viene de su complejo de inferioridad que se activa a partir de la mirada de osefina. Por eso decidió que su placer en las orgías sería la más dura humillación para Josefina y así renunció carnalmente a su bella esposa. Ella es caracterizada por Baltasar como una posible víctima de su poder, pero al encuadrar a su esposa con el resto de las mujeres que participan en las orgías rápidamente se puede establecer que ella es víctima del propio poder que le concedió su posición. En cuanto a la mención de una mulata en las orgías, apunta al hecho de que no sólo había un blanqueamiento psicológico sino también uno racial en el Puerto Rico del siglo XVIII. En el testimonio literario que deja un fragmento del drama de Alejandro Juliá $\mathrm{M}$ arín titulado $\mathrm{El}$ héroe Baltasar que aparece en esta novela, se puede observar que la mirada del blanco visualiza al negro como un objeto. En ella no hay sólo un sentimiento de superioridad sino también de temor. Baltasar le dice al O bispo, "conozco el miedo que ustedes sienten cada vez que miran a un negro" (32). Es través de la mirada que se llega a la negro-fobia y a la auto negro-fobia. D e manera que muchos de los problemas de la identidad puertorriqueña y sus inherentes anomalías sehacen presentes en esta novela. El héroe mítico del relato, en su ascenso y descenso del poder, 
hace una serie de renuncias, todas relacionadas con el poder que merecen la atención de este estudio. La primera es de gran significación ya que requiere del individuo la transmutación de su propia identidad y a su vez representa el microcosmo de una serie de anomalías psicológicas en la identidad puertorriqueña. Para cuando el 0 bispo Larra ya había creado el mito del milagroso héroe Baltasar sólo faltaba concertar su matrimonio con Josefina para completar la primera fase de su plan. Al aceptar el enlace, Baltasar cometió la primera renuncia. D e acuerdo con el narrador "en primer lugar renunciaba a su propia raza, a su propio pueblo" (9). Al desistir de su raza absorbe por completo las convenciones sociales e ideológicas de la al ta sociedad. El tono testimonial que caracteriza a este texto lo explica de la siguiente manera:

este intruso tendría que renunciar a su negritud, a la cultura de los barracones, que es un trasunto de las antiquísimas culturas de la costa occidental de Africa, y asumir todas las fórmulas sociales, culturales y religiosas de la "buena sociedad" blanca del Puerto Rico colonial del siglo XVIII (9).

$\mathrm{H}$ ay, en la psique de Baltasar, una desconexión total y temporal con su propia raza cuando renuncia a la memoria de su padre, Ramón M ontañez, capitán de la primera revuelta de negros. $\mathrm{H}$ acia el final de la novela se une Baltasar M ontañez a su padre y a otros líderes negros que, como ellos y no por pura coincidencia, comenzaron para las mismas fechas a tratar de ejercitar el derecho a voz por medio de la violencia.

Cuando se examinan los estudios que relacionan la identidad y la mimesis, se encuentra en ellos la manera exagerada en que los subalternos imitan a la elite. Baltasar le rinde tributo al estilo hiperbólico de la intelectualidad española del siglo XVIII exagerándolo, característica que desemboca en sus manuscritos de su "insegura pluma" (19). La gran cultura que adquirió en pocos años se convirtió en "una patética caricatura" (19) deintelectualidad española. La misiva que el $O$ bispo Larra le envía al Secretario de Gobierno Prats, donde intenta convencerlo de la utilidad del matrimonio de su hija, permite un acercamiento al psicoanálisis que hace de Baltasar. El O bispo lo califica como traidor de su raza y halagador de la monarquía española. Pero más importante es que en una frase, describiendo al futuro esposo como "una patética caricatura", muestra la problemática de la subordinación psicológica. M ás adelante, en referencia a las virtudes del negro, dice: "Es alto ingenio que odia su oscurísima piel" (25). El sentido deinferioridad de Baltasar está muy bien documentado en el texto, cosa que prueba que esa sumisión y el odio por su oscurísima piel es producto del proyecto de blanqueamiento psicológico que se instituye en el Caribe colonial. Para ahondar en los problemas de la identidad puertorriqueña es necesario pro- 
fundizar en las dificultades que sufrió la identidad de la raza negra en Puerto Rico en tiempos coloniales y específicamente en el siglo XVIII. La retórica de deshumanización y de animalización del negro, aceptable por la mayoría de la población blanca de la isla, también comenzó a ser aceptada por los mismos negros y mulatos. Este fenómeno y sus resultados se pueden detectar en muchas de las peculiaridades del negro Baltasar. D e acuerdo con el cronista, lo que los acercaba a la humanidad era el contacto o la convivencia con la raza blanca. La consecuencia de tal bombardeo psicológico se puede percibir en el odio que expresa Baltasar por su propia raza y el sentido de inferioridad que siente ante Josefina. Citando al diario de Baltasar, el conferencista comenta que el cuerpo de Josefina se convirtió en "tentación de inferioridad" (54). El concepto de biopoder de Foucault prueba ser muy efectivo en el desarrollo de temas sobrela identidad negra en Puerto Rico. La función principal del biopoder es controlar los cuerpos y las mentes de los sujetos o subalternos. No hay duda de que el personaje de Baltasar, siendo un perfil psicológico del negro, es muestra suficiente del efecto de las convenciones raciales de la época y su propia enajenación. La antipatía a su propia raza no era sino el resultado del biopoder. Los discursos raciales coloniales encontraron, en la conciencia del negro o del subalterno, una aceptación que afectó por siempre las dinámicas de la identidad racial. Shohat indica que "las opresiones raciales o nacionales reflejan los patrones coloniales" (2000: XX). Estas son la negación de una identidad separada del subordinado; la inculcación dentro del grupo subordinado de la creencia deque su propia cultura e identidad son inferiores a la de la elite, o sea, se crea un complejo deinferioridad; y la aceptación, por el grupo subordinado, delaidentidad y los valores de la elite. En Black skin white mask, Fanon dice al respecto que "after having been the slave of the white man, he (the subordinate) enslaves himself by accepting these notions and beliefs about his own inferiority" (1967: 170).

La presencia de esta temática a través de más de un siglo en la literatura puertorriqueña indica que es una situación que, por lo menos para los literatos isleños, queda por resolver. Es por esto queeste texto proponela reconstrucción de la identidad racial de Puerto Rico. Parodiando y subvirtiendo a la historiográfica de antaño, se une a las corrientes contemporáneas que buscan en la intrahistoria una historia más objetiva y más completa del pasado isleño. El mero hecho de que Rodríguez Juliá presente tal temática a un lector del siglo XXI significa que tanto la percepción histórica como la percepción racial del puertorriqueño aún están trastocadas. Esta novela, además, prueba definitivamente la existencia de una relación directa entre el poder y la identidad racial nacional. El poder se descentraliza, dándole así al negro un puesto importante en el génesis del perfil racial y cultural. La utilización de la retórica racial del 
siglo XVIII para el lector del siglo XXI activa en la memoria colectiva puertorriqueña una reorganización de su composición racial.

La definición que da Víctor Bravo a la parodia, al conectarla a la identidad, valida el acercamiento de este análisis a la carnavalización en La renuncia del héroe Baltasar. Bravo indica que la parodia es "imitación pero, en el mismo instante, puede ser transformación. No es sino un discurso desmitificador, desde lo colectivo de las elites del poder" (1987: 117). Rodríguez Juliá desmitifica a la historia oficial, ciertamente degrada los procesos creadores de la historiográfica y parodia sus el ementos constitutivos. B ravo indica que paraJ acques D errida la parodia es un volver a escribir deconstruyendo, desmontando y negando los valores del modelo (118). Rodríguez Juliá deconstruye la historia puertorrique ña, desmonta las dinámicas historiográficas y niega la fallida pero aceptada composición racial de la nación. Este relato se podría considerar como un nuevo proyecto fundacional y la antítesis de El jíbaro, novela fundacional puertorriqueña escrita en 1849. La renuncia del héroe Baltasar propone una esencialidad, racialmente hablando, distinta a la que ofrecela novela de M anuel Alonso. Rodríguez Juliá le da importancia histórica y racial a la negritud como parte importante de la esencia puertorriqueña. Su novela viene a conformar una pieza importantísima en el rompecabezas que literaturiza la creación y desarrollo de la identidad nacional y sus inherentes anomalías. La identidad del negro y del mulato está completamente enajenada y supeditada al proyecto de blanquitud por el condicionamiento psicológico colectivo durante la colonia y que pervive hoy.

\section{REFERENCIAS}

Alonso, M anuel. 2001. El jíbaro. Río Piedras: Ediciones H uracán.

Baker, M . 1981. The new racism: Conservatives and the ideology of the tribe. London: Junction Books.

Bravo, Víctor. 1987. Los poderes de la ficción: Para una interpretación de la literatura fantástica. C aracas: M onte Avila Editores.

D anaher, G eoff; Schirato, Tony y W ebb, Jen. 2000. U nderstanding Foucault. London: Sage Publications.

Fanon, Frantz. 1967. Black skin whitemasks Trad. por C harles Lam M arkmann. N ew York: Grove Press, Inc.

Rodríguez Juliá, Edgardo. 1986. La renuncia del héroe Baltasar. Río Piedras: Editorial Cultural.

Shohat, Ella. 2000. Thepreoccupation of the postcolonial studies. Edi. por FawziaAfzalKhan y Kal pana Seshadri-C rooks. D urham: D uke U niversity Press.

Sued Badillo, Jalil y López Cantos, Angel. 2001. Puerto Rico negro. Río Piedras: Editorial Cultural.

Trouillot, M ichel-Rolph. 1995. Silencing the past: Power and the production of history. Boston: Beacon Press. 